\title{
IMPACTOS DA LEGITIMAÇÃO FUNDIÁRIA NO MEIO AMBIENTE URBANO
}

\section{IMPACTS OF LAND LEGITIMATION IN THE URBAN ENVIRONMENT}

\section{VALMIR CÉSAR POZZETTI}

Doutor e Mestre em Direito Ambiental pela Universtè de Limoges/França; Professor Adjunto C da UFAM - Univ. Federal do Amazonas e da UEA - Universidade do Estado do Amazonas. E-mail: v_pozzetti@hotmail.com

\section{REBECCA LUCAS CAMILO SUANO LOUREIRO}

Mestranda em Direito Ambiental pela Universidade do Estado do Amazonas. Pósgraduada em Direito Público pela Universidade do Sul da Santa Catarina - UNISUL. Pós-graduanda em Direito Notarial e Registral pela Universidade Damásio. ManausAM. E-mail: rsuano@gmail.com

\section{RESUMO}

Objetivo: Esta pesquisa tem como objetivo identificar quais os possíveis reflexos da legitimação fundiária dos núcleos urbanos informais consolidados ao meio ambiente.

Metodologia: A metodologia utilizada, quanto aos meios, é o método dedutivo, por meio de análise doutrinária, bibliográfica e normativa. Quanto aos fins, a metodologia é qualitativa.

Resultados: A conclusão a que chegou é de que a legitimação fundiária é um instrumento frágil, que não solucionará o problema da moradia digna no Brasil e trará consequências graves ao meio ambiente das cidades.

Contribuições: A exclusão do estudo ambiental e dos projetos de urbanização em todos os casos que não envolvam áreas de proteção ambiental ocasionará um crescimento desordenado e de impossível correção, e para que haja uma real observância dos preceitos constitucionais é necessário que o Estado cumpra o seu 
dever de organização das cidades e pare de procurar mecanismos para aplacar as obrigações não cumpridas.

Palavras-chave: Legitimação fundiária; meio ambiente urbano; ordenamento territorial; regularização urbana.

\section{ABSTRACT}

Objective: This research aims to identify which are the possible reflexes of land tenure legitimacy of informal urban centers consolidated to the environment.

Methodology: The methodology used is deductive, through doctrinal, bibliographic and normative analysis. As for the purposes, the methodology is qualitative.

Results: The conclusion reached is that land tenure is a fragile instrument, which will not solve the problem of decent housing in Brazil and will have serious consequences for the environment of cities.

Contributions: The exclusion of the environmental study and urbanization projects in all cases that do not involve areas of environmental protection will cause a disorderly growth and of impossible correction, and in order to exist a real observance of the constitutional law, it is necessary that the State complies with its duty of organizing cities and stop looking for mechanisms to appease unfulfilled obligations.

Keywords: Land tenure legitimization; urban environment; land legal system; urban regularization.

\section{INTRODUÇÃO}

A regularização fundiária urbana guarda íntima relação com os dilemas do Poder Público no cumprimento de deveres constitucionais por vezes conflitantes.Se ao Estado cabe, por um lado, fazer respeitar o princípio do ordenamento territorial e do meio ambiente sadio e equilibrado, por outro lado, cabe-Ihe garantir aos cidadãos o direito à moradia digna e ao desenvolvimento econômico sustentável.

Com o advento da Lei №. 13.465/2017, o Estado passou a contar com uma diversidade de medidas que objetivam conferir maior flexibilidade à regularização 
fundiária. O normativo introduziu no ordenamento jurídico brasileiro o instituto da legitimação fundiária, forma originária de aquisição da propriedade imobiliária, conferida por ato discricionário do Poder Público àqueles que possuirem área integrante de núcleo urbano informal consolidado. A regularização fundiária é, portanto, um conjunto de medidas possíveis para atribuir-se direito de propriedade e titulação às pessoas que ocupam áreas irregulares ou clandestinas.

Não obstante tais medidas, o reconhecimento de direito sociais deve observar uma série de preceitos e outros princípios que devem ser sopesados e analisados cuidadosamente por quem interpretará a norma jurídica e delineará as políticas públicas. É necessário que haja equilíbrio entre os direitos individuais e os direitos de toda a coletividade.

O objetivo desta pesquisa é analisar este novel instituto de aquisição de propriedade em cotejo com o direito fundamental à moradia digna e o Princípio do Desenvolvimento Sustentável, bem como com o Princípio do Ordenamento Territorial e o direito ao meio ambiente urbano sadio e equilibrado.

A problemática que envolve o tema: quais seriam os possíveis reflexos, no meio ambiente urbano, da legitimação fundiária dos núcleos urbanos informais consolidados?

A temática abordada justifica-se pela necessidade de discutir-se os impactos que a não observância do princípio constitucional do ordenamento territorial poderia ocasionar ao meio ambiente das cidades, especialmente em relação aos ocupantes que se beneficiarão da aquisição de propriedade por meio da legitimação fundiária.

A metodologia utilizada nesta pesquisa é o método dedutivo, analisando-se as premissas gerais aplicáveis a hipóteses concretas. Quanto aos meios, será doutrinária e bibliográfica, com uma análise normativa, vez que os conceitos mencionados derivam em grande parte das próprias normas, incluindo-se a Constituição de 1988 - e a Lei de Regularização Fundiária.

Quanto aos fins, a pesquisa será qualitativa, em virtude da necessidade de verificar, interpretar, analisar, compreender e explicar os possíveis impactos no meio ambiente urbano que a não observância do princípio constitucional do ordenamento 
territorial poderá causar quando da regularização fundiária nas grandes cidades, com base neste novo marco legal.

\section{A ORGANIZAÇÃO LEGAL DO DIREITO URBANÍSTICO}

A Constituição dispõe em seu texto de uma série de princípios ambientais e urbanísticos que devem ser analisados, para que se possa traçar as primeiras considerações sobre a regularização fundiária.

Nos títulos I e II, atinentes aos princípios fundamentais e aos direitos e às garantias fundamentais, a Constituição elenca a dignidade da pessoa humana como fundamento da República, a necessidade de garantir o desenvolvimento nacional como objetivo fundamental, a função social da propriedade como direito fundamental e o direito à moradia como direito social.

$\mathrm{O}$ art. 21, inciso $\mathrm{XX}$ da Constituição define que competirá à União estabelecer normas gerais sobre desenvolvimento urbano, incluindo-se transporte urbano, saneamento básico, ordenamento territorial e habitação.

Já o art. 24 da Constituição dispõe que é competência concorrente da União, dos Estados e do Distrito Federal legislar sobre direito urbanístico. Tal dispositivo possibilita que os Estados estabeleçam organização e planejamento sobre as cidades, ainda que de forma mínima.

Por sua vez, o art. 30 da Constituição fixa que será da competência dos municípios a promoção adequada do ordenamento territorial, mediante planejamento e controle do uso, do parcelamento e da ocupação do solo urbano.

Ainda nesse sentido, a Constituição estabelece normas sobre a política urbana, relacionadas nos arts. 182 e 183, nas quais fixa as diretrizes em relação ao objetivo de ordenar o desenvolvimento das funções sociais da cidade e garantir o bem-estar de seus habitantes; determina a instituição de um plano diretor a ser aprovado pelo Poder Legislativo municipal, que será o instrumento básico da política de expansão e desenvolvimento urbano. Além disso, dispõe que a função social da 
propriedade urbana haverá de pressupor 0 atendimento das exigências de ordenação do plano diretor.

Por fim, no art. 225, a Constituição dispõe sobre o direito garantido a todos os cidadãos de um meio ambiente ecologicamente equilibrado, essencial à qualidade de vida da população, e que deve ser protegido e preservado pela sociedade e pelo Poder Público,a fim de que as presentes e as futuras gerações possam utilizá-lo.

$\mathrm{Da}$ análise constitucional, percebe-se que houve a necessidade se estabelecer-se, por leis federais, as normas gerais a serem observadas quanto à organização dos estados-membros, no que se refere ao meio ambiente de suas cidades. Em razão dessa demanda, foi editada a Lei o․ 10.257/2001, o Estatuto das Cidades, que regulamenta os art. 182 e 183 da Constituição.

O Estatuto das Cidades (BRASIL, 2001) define que o objetivo da política urbana está diretamente relacionado ao pleno desenvolvimento das funções sociais da cidade e da propriedade urbana. O Estatuto das Cidades enumera diversas diretrizes que devem ser observadas, de modo que se alcance esse pleno desenvolvimento:

Art. $2^{\circ}$. A política urbana tem por objetivo ordenar o pleno desenvolvimento das funções sociais da cidade e da propriedade urbana, mediante as seguintes diretrizes gerais: I - garantia do direito a cidades sustentáveis, entendido como o direito à terra urbana, à moradia, ao saneamento ambiental, à infra-estrutura urbana, ao transporte e aos serviços públicos, ao trabalho e ao lazer, para as presentes e futuras gerações; [...] omissis IV - planejamento do desenvolvimento das cidades, da distribuição espacial da população e das atividades econômicas do Município e do território sob sua área de influência, de modo a evitar e corrigir as distorções do crescimento urbano e seus efeitos negativos sobre o meio ambiente; [...] omissis VI ordenação e controle do uso do solo, de forma a evitar: a) a utilização inadequada dos imóveis urbanos; b) a proximidade de usos incompatíveis ou inconvenientes; c) o parcelamento do solo, a edificação ou o uso excessivos ou inadequados em relação à infraestrutura urbana; d) a instalação de empreendimentos ou atividades que possam funcionar como pólos geradores de tráfego, sem a previsão da infra-estrutura correspondente; e) a retenção especulativa de imóvel urbano, que resulte na sua subutilização ou não utilização; f) a deterioração das áreas urbanizadas; g) a poluição e a degradação ambiental; h) a exposição da população a riscos de desastres. [...] omissis XIV - regularização fundiária e urbanização de áreas ocupadas por população de baixa renda mediante 0 estabelecimento de normas especiais de urbanização, uso e ocupação do 
solo e edificação, consideradas a situação socioeconômica da população e as normas ambientais; [...] omissis.

O Estatuto das Cidades destaca ainda, em seu art. 4º, inciso V, alínea "q", que a regularização fundiária é instituto jurídico e político previsto como instrumento legal da política urbana.

Consequentemente, direitos e princípios como o da moradia digna, do desenvolvimento sustentável, da função social da propriedade e do ordenamento territorial passam a estabelecer entre si uma intrincada relação.

\subsection{O DIREITO À MORADIA DIGNA}

A exploração econômica marcou a ocupação do solo brasileiro. Historicamente, fruto de colonização e de exploração, o território brasileiro foi utilizado para a retirada de recursos naturais e minerais que geravam lucro para seu colonizador. Por este motivo, é fácil afirmar que o acesso formal à terra sempre foi garantido aos que detinham condições financeiras. Por esta razão, aqueles que não possuíam capital eram marginalizados, exercendo a ocupação irregular de solos que não apresentavam interesse financeiro para o Poder Público.

Com o processo de industrialização nacional e o êxodo rural resultante, as populações passaram a ocupar os centros urbanos, habitando, de maneira desordenada, os locais onde se estabeleciam. Por esta razão, durante muito tempo, as populações eram removidas dessas ocupações irregulares e iam estabelecendose em lugares diversos.

Neste sentido, Silva (2018, p. 21), afirma que "no Brasil o fenômeno urbano vincula-se à política de ocupação e povoamento da Colônia e sua evolução liga-se estreitamente aos ciclos econômicos brasileiros".

O processo efetivo de urbanização, considerado a partir de uma política social de habitação, só teve início no Brasil a partir da década de 1930, quando o Estado passou a financiar a criação de moradias para que os residentes em favelas fossem realojados. Entretanto, a política não foi suficiente e a população 
marginalizada adotou, como solução para o problema da moradia, o loteamento irregular na periferia, a ocupação ilegal de terras e a autoconstrução de moradias. (MOTA; ALCINO E MOURA, 2018)

Mota et al. (2018, p. 9) prosseguem, neste passo, afirmando:

As tentativas de regulamentação do uso da terra [...] apresentaram-se como virtualmente fracassadas no Brasil, [...] em razão da falta de fiscalização capaz de fazer prevalecer às restrições e sua utilização não para a melhoria das condições de vida da cidade, mas para a exclusão da comunidade carente das áreas de interesse do mercado.

Com o passar do tempo, o Poder Público deu início às discussões relacionadas às ocupações irregulares, destacando a necessidade de reconhecer-se o direito à moradia digna, entendida não só como um lugar que garanta condições apropriadas à sobrevivência, mas também como um lugar que proporcione segurança jurídica aos seus ocupantes.

$\mathrm{O}$ direito à moradia passa a ter concepção mais ampla - o conceito em sentido estrito, cingido apenas à habitação, deixa de ser o foco principal das normas. Passa-se a identificar a necessidade de políticas públicas nos núcleos habitacionais, a necessidade de prestação de serviços básicos de saneamento, luz elétrica, água encanada e de todos os equipamentos públicos, a fim de que se possa falar em condições dignas de sobrevivência e em observância das garantias fundamentais dos seus habitantes.

Neste sentido, o direito à moradia é tomado por comando constitucional corolário da dignidade da pessoa humana. A moradia digna torna-se um fim a ser atingido pelo Estado. Com base na dignidade humana, o Poder Público impõe-se a obrigação de propiciar condições mínimas de existência às pessoas, considerandose aqui os mecanismos que devem ser disponibilizados pelo Estado, para o alcance da qualidade de vida. 


\subsection{O PRINCÍPIO DO ORDENAMENTO TERRITORIAL}

A Constituição prevê, em seu art. 30, o Princípio do Ordenamento Territorial, cuja observância é da competência do município. Além da previsão do art. 30 da Constituição, o art. 182 da Carta Magna aponta a necessidade de ordenação da cidade conforme expresso no plano diretor.

A legislação infraconstitucional também dispõe sobre a necessidade de realizar-se o planejamento do desenvolvimento das cidades e da distribuição espacial da população, de maneira a evitar distorções do crescimento urbano e efeitos negativos sobre o meio ambiente. Neste sentido, o Estatuto das Cidades fixa normas de ordenamento e controle de uso do solo.

$\mathrm{O}$ ordenamento territorial passa ser entendido como um planejamento da expansão das cidades, de maneira que a infraestrutura existente seja aproveitada e os recursos naturais limitados sejam conservados. O planejamento de uma atividade deve ser a parte inicial de qualquer ação. O mesmo verifica-se quando se pensa na atividade urbana. O Poder Público tem o dever de elaborar um plano de ação para entender os objetivos que pretende alcançar e verificar os meios que possui para executá-los.

Silva (2018, p. 33), ao tratar sobre o planejamento das cidades, afirma que é "a ordenação do solo, que, em essência, revela o conteúdo fundamental do planejamento no que tange à disciplina do uso e ocupação dos espaços habitáveis".

É importante salientar que o ordenamento citadino vai muito além de plantas como locais para edificação, envolve atividades de humanização e de adequação dos ambientes.

O plano a ser instrumentalizado é imposição constitucional, aprovado por lei, com diretrizes de cumprimento obrigatório para o setor público. Silva $(2018$, p. 93) explicita. Ainda. que o:

[...] planejamento é um processo técnico instrumentado para transformar a realidade existente no sentido de objetivos previamente estabelecidos noção que se aplica ao planejamento em geral, e, portanto, também ao planejamento urbanístico" e finaliza "na medida em que esse processo 
tende a consubstanciar-se em planos é que permite afirmar que o planejamento urbanístico não é um simples fenômeno técnico, mas um verdadeiro processo de criação de normas jurídicas. (SILVA, 2018, p.93).

Para o jurista, o planejamento urbanístico está dividido em uma fase preparatória, manifestada nos planos gerais normativos, e uma fase vinculante, relacionada com a execução do plano.

No Brasil, o plano diretor será um dos instrumentos da política urbana utilizados na consecução da ordenação das cidades. Sua observância será primordial para o respeito ao Princípio do Ordenamento Territorial e o alcance de todos direitos fundamentais derivados dele, tendo como "função sistematizar o desenvolvimento físico, econômico e social do território municipal" (SILVA, 2018, p.140), com obrigações específicas, como a de definir a função social da propriedade e sistematizar a fiscalização de seu cumprimento, visando assegurar condições de vida adequadas para os habitantes de um município.

\subsection{O PRINCÍPIO DA FUNÇÃO SOCIAL DA PROPRIEDADE}

Constitucionalmente previsto no art. $5^{\circ}$, inciso XII, o direito à propriedade participa do rol de direitos fundamentais, desde que atenda à sua função social. Além de constituir princípio fundamental, a função social da propriedade está positivada no rol de princípios do art. 170 da Constituição, que norteia a ordem econômica, e na previsão do art. 184, sobre a política agrícola e fundiária, que tutela o imóvel rural e sua função social. Entretanto, interessa aqui a função social da propriedade urbana.

A Constitiuição prevê, em seu art. 182, $\S 2^{\circ}$., que a propriedade urbana que atenda às exigências fundamentais de ordenação das cidades previstas no plano diretor cumprirá a sua função social.

Para que se possa entender melhor sobre a função social da propriedade urbana, é necessário que se conheçam alguns conceitos.

Inicialmente, faz-se mister destacar que será considerada propriedade urbana aquela destinada ao exercício de funções urbanísticas. Como funções 
urbanísticas, podem ser entendidas as atividades de circular, de habitar, de trabalhar e de lazer.

Por plano diretor, entende-se o instrumento municipal, aprovado pela Câmara Legislativa, que versa sobre a política de desenvolvimento e expansão urbana, que integrará o processo de planejamento municipal.

A Lei ㄲo. 10.257/2001, em seu art. 39 e seguintes, estabelece as diretrizes mínimas que devem constar do plano diretor. Destaca-se a delimitação de áreas urbanas onde poderão ser realizados o parcelamento, a edificação ou a utilização compulsórios do solo urbano não edificado, subutilizado ou não utilizado, considerando a existência de infraestrutura e de demanda para sua utilização.

Ressalta-se que a propriedade deve obediência ao plano diretor. Sendo este um instrumento público, com deveres a serem observados pelos particulares com limitações legais ao direito de propriedade, pode-se afirmar que haverá uma sobreposição do interesse coletivo sobre o interesse daquele que detém o direito real. Sobre o tema, Spantigati citado por Silva (2018, p. 77), afirma:

\begin{abstract}
Bem expressiva nesse sentido é a lição de Spantigatti, tendo em vista o art. 3 ‥ da Constituição Italiana, segundo o qual a função social da propriedade urbana "constitui um equilíbrio entre 0 interesse privado e 0 interesse público que orienta a utilização do bem e predetermina seus usos, de sorte que se pode obter, nos modos de vida e nas condições de moradia dos indivíduos, um desenvolvimento pleno da personalidade. Nesta construção está claro que o interesse do indivíduo fica subordinado ao interesse coletivo por uma boa urbanização, e que a estrutura interna do direito de propriedade é um aspecto instrumental no respeitante ao complexo sistema da disciplina urbanística
\end{abstract}

Desta forma, a ideia de função social da propriedade é reflexo da preponderância do interesse coletivo sobre o interesse privado. Assim, a propriedade urbana cumprirá a sua função social se, e apenas se, propiciar habitação em condições que garantam a existência de um conteúdo mínimo à dignidade humana e se houver um equilíbrio entre os interesses privados e públicos que orientam a utilização do bem de acordo com as necessidades do desenvolvimento urbano. 


\subsection{O PRINCÍPIO DO DESENVOLVIMENTO SUSTENTÁVEL}

O ideário do desenvolvimento sustentável, de maneira generalizada, foi mencionado pela primeira vez no Relatório Brundtland, em 1987.

A primeira Ministra da Noruega, Gro Harlem Brutland, foi designada pela Organização das Nações Unidas para chefiar a Comissão Mundial sobre o Meio Ambiente e Desenvolvimento e, no final dos estudos, elaborou o mencionado relatório. Naquele documento, conhecido como "Nosso Futuro Comum", foi proposto que o desenvolvimento seria sustentável se atendesse às necessidades do presente sem comprometer a possibilidade de as gerações futuras também terem as suas necessidades atendidas. (RELATÓRIO BRUNDTLAND, 1988)

Um dos pontos cruciais do estudo é ressaltar que o modelo de desenvolvimento adotado pelos Estados industrializados e os em desenvolvimento causam riscos do uso imoderado dos recursos naturais, sem considerar a capacidade de suporte do ecossistema.

Além disso, em 1987, o Relatório Brundtland demonstrou preocupações com problemas ambientais gerados pelo desequilíbrio do modelo desenvolvimentista, dentre eles, o aquecimento global e a destruição da camada de ozônio, que estavam ocorrendo em velocidade muito superior à avaliação e propositura de soluções.

Conforme os estudos iam concretizando-se e o relatório era elaborado, restou claro que, além dos limites de bem-estar da sociedade, também são necessários limites na utilização dos recursos naturais, para que sejam preservados e aqueles capazes, sejam renovados.

Com as novas ideias e o surgimento do pensamento sobre 0 desenvolvimento sustentável, passou-se a falar sobre uma conciliação entre o desenvolvimento econômico e a preservação ambiental.

$\mathrm{Na}$ Conferência das Nações Unidas sobre Meio Ambiente e Desenvolvimento, a Cúpula da Terra de 1992 - Eco-92, no Rio de Janeiro, foi incorporado ao estudo ambiental mundial o Princípio do Desenvolvimento Sustentável. Passou-se a afirmar então que o Desenvolvimento Sustentável é 
aquele que busca equilíbrio entre a proteção ambiental e o desenvolvimento econômico.

Em 2002, após a Cúpula Mundial sobre Desenvolvimento Sustentável, realizada em Johanesburgo, consolidou-se o entendimento de que só seria possível alcançar um desenvolvimento sustentável se fossem observados três pontos principais: desenvolvimento econômico, desenvolvimento social e proteção ambiental.

No Brasil, o desenvolvimento sustentável é um princípio constitucional observado da interpretação sistemática de diversos dispositivos:

\begin{abstract}
PREÂMBULO. Nós, representantes do povo brasileiro, reunidos em Assembléia Nacional Constituinte para instituir um Estado Democrático, destinado a assegurar o exercício dos direitos sociais e individuais, a liberdade, a segurança, o bem-estar, o desenvolvimento [...] omissis. Art. $3^{\circ}$ Constituem objetivos fundamentais da República Federativa do Brasil: [...] omissis II - garantir o desenvolvimento nacional; Art. 170. A ordem econômica, fundada na valorização do trabalho humano e na livre iniciativa, tem por fim assegurar a todos existência digna, conforme os ditames da justiça social, observados os seguintes princípios: [...] omissis VI - defesa do meio ambiente, inclusive mediante tratamento diferenciado conforme 0 impacto ambiental dos produtos e serviços e de seus processos de elaboração e prestação; [...] Art. 182. A política de desenvolvimento urbano, executada pelo Poder Público municipal, conforme diretrizes gerais fixadas em lei, tem por objetivo ordenar o pleno desenvolvimento das funções sociais da cidade e garantir o bem-estar de seus habitantes. [...] Art. 225. Todos têm direito ao meio ambiente ecologicamente equilibrado, bem de uso comum do povo e essencial à sadia qualidade de vida, impondo-se ao Poder Público e à coletividade o dever de defendê-lo e preservá-lo para as presentes e futuras gerações.
\end{abstract}

Da interpretação do texto constitucional, percebe-se que o princípio do desenvolvimento sustentável está intimamente ligado ao princípio da dignidade da pessoa humana. Assim, a distribuição de bens e riquezas por uma sociedade deve atender toda a população, principalmente àqueles que necessitam dos direitos prestacionais do Estado.

O artigo $3^{\circ}$. da Constituição, ao tratar sobre os objetivos fundamentais da República, apresenta normas de caráter cogente para o ente estatal. A construção de uma sociedade livre, justa e solidária, a erradicação da pobreza e da 
marginalização e a redução das desigualdades sociais e regionais são preceitos que envolvem diretamente o desenvolvimento do País.

O Princípio do Desenvolvimento Sustentável, analisado sob a ótica conjunta do direito urbanístico e do direito ambiental, compreende um significado de sustentabilidade urbana, devendo combinar cidades ambiental e socialmente justas para as gerações presentes e futuras, envolvendo condições ambientais, socioeconômicas, políticas e culturais desejadas.

Segundo Virginia Maclaren, citada por Ferreira (2005, p. 02), descreve:

não existe uma única e "melhor" definição de sustentabilidade urbana, porque diferentes comunidades desenvolvem conceptualizações mais ou menos diversas de "sustentabilidade urbana", dependendo das suas actuais condições económicas, ambientais e sociais e dos seus juízos de valor. Deste modo, um conjunto de indicadores seleccionados para medir o progresso no que diz respeito aos objectivos da "sustentabilidade" a atingir por uma comunidade podem não ser necessariamente adequados para medir o progresso de outra comunidade. No entanto, a autora põe em evidência que existem alguns indicadores que devem ser comuns a todas as comunidades e que dizem respeito a aspectos ambientais, económicos e sociais e que devem possuir as seguintes características: serem integradores, isto é, reflectirem as relações existentes entre as dimensões económicas, ambientais e sociais da "sustentabilidade"; terem em conta o futuro, pois devem atender aos princípios da equidade intergeracional; terem em conta a equidade intrageracional e ainda serem estabelecidos mediante a contribuição de muitos membros da comunidade.

Ferreira (2005, p. 4/5) prossegue afirmando:

O "desenvolvimento sustentável" implica, portanto, que os cidadãos conheçam as: Relações entre sociedade, economia e ambiente e entre as suas vidas e as vidas das populações que vivem noutras partes do mundo; Necessidades e direitos das gerações presentes e futuras; Relações entre poder, recursos e direitos humanos; Consequências locais e globais de tudo o que fazem e as respostas que os indivíduos e as organizações podem dar aos problemas locais e globais.

O uso da propriedade não pode desvincular-se da conservação ambiental. $\mathrm{O}$ desenvolvimento econômico-social e a conservação do meio ambiente devem ser compatibilizados, de maneira que o desenvolvimento propicie um nível de vida que 
supra as necessidades essenciais dos seres humanos, individual e coletivamente, nas presentes e futuras gerações.

\title{
3 A REGULARIZAÇÃO FUNDIÁRIA URBANA E A LEI №. 13.465/2017
}

A regularização fundiária teve regulamentação em diversos diplomas nacionais. No âmbito das cidades, a Lei no. 6.766/1979, Lei de Parcelamento de Uso do Solo Urbano, editada em 1979, teve grande importância na previsão de diversos conceitos legais e estruturas de regularização fundiária urbana. Todavia, a Constituição foi a grande responsável pela sistematização do tema. Neste sentido, Mota et. al. (2018, p. 53) esclarecem:

\begin{abstract}
Foi a reforma urbana preconizada pela Constituição e a previsão nela mesma de institutos de regularização urbanística e fundiária, como a usucapião pro morare e a base para a concessão de uso especial para fins de moradia, de princípios estruturantes, como o da função social da propriedade urbana e da Cidade e da justa distribuição dos bônus e ônus urbanísticos, que se elevou a matéria ao status fundamental, a partir do qual se pode e deve interpretar toda a legislação infraconstitucional.
\end{abstract}

No que tange à legislação infraconstitucional pós Constituição de 1988, a Lei no. 11.977/2009, conhecida como Programa Minha Casa Minha Vida estabeleceu um importante marco teórico, criando mecanismos de incentivo à produção e aquisição de novas unidades habitacionais, requalificação de imóveis urbanos e produção ou reforma de habitações rurais, para famílias que possuam a renda estipulada na norma.

A Lei no. 13.465/2017 passou a ser o diploma responsável por instituir as normas gerais e procedimentos aplicáveis à Regularização Fundiária Urbana Reurb. Deve-se lembrar que o procedimento foi expressamente mencionado como sendo instituto jurídico e político para realização da política urbana municipal pelo Estatuto das Cidades. 
Conceitualmente, a regularização fundiária urbana é uma política pública que tem como fim titular os ocupantes de áreas irregulares, núcleos urbanos informais, consolidados ou não, de modo a garantir condições dignas de sobrevivência, principalmente no que tange à cidadania e à segurança, e a responsabilidade ambiental, verificada na exploração sustentável dos recursos naturais. Para a regularização fundiária urbana prevista na lei, independe da localização dos núcleos urbanos informais, permitindo-se titulação de ocupantes de assentamentos em área pública, privada, urbana, de expansão urbana ou rural, ainda que em discrepância com o plano diretor.

A Lei no. 13.465/2017 ingressou no ordenamento jurídico brasileiro com o propósito de garantir moradia com condições mínimas de dignidade e segurança aos ocupantes dos núcleos urbanos informais:

Art. 9o Ficam instituídas no território nacional normas gerais e procedimentos aplicáveis à Regularização Fundiária Urbana (Reurb), a qual abrange medidas jurídicas, urbanísticas, ambientais e sociais destinadas à incorporação dos núcleos urbanos informais ao ordenamento territorial urbano e à titulação de seus ocupantes.

É necessário destacar que a Lei estabeleceu uma série de conceitos para que sobre eles não recaiam dúvidas. Dentre os termos definidos, pode-se destacar: 1) o núcleo urbano informal como "aquele clandestino, irregular ou no qual não foi possível realizar, por qualquer modo, a titulação de seus ocupantes, ainda que atendida a legislação vigente à época de sua implantação ou regularização"; 2) o núcleo urbano informal consolidado como "aquele de difícil reversão, considerados o tempo da ocupação, a natureza das edificações, a localização das vias de circulação e a presença de equipamentos públicos, entre outras circunstâncias a serem avaliadas pelo Município"; e, 3) a demarcação urbanística como um procedimento que visa "identificar os imóveis públicos e privados abrangidos pelo núcleo urbano informal e a obter a anuência dos respectivos titulares de direitos inscritos na matrícula dos imóveis ocupados, culminando com averbação na matrícula destes imóveis da viabilidade da regularização fundiária, a ser promovida a critério do Município". 
No cenário urbano brasileiro percebe-se que as ações de políticas públicas para alcançar a moradia digna aos cidadãos foram inadequadas à solução do problema habitacional observado.

Visando dar cumprimento aos ditames constitucionais de moradia digna, a Lei o. 13.465/2017 constituiu doze objetivos da Reurb a serem observados pelos entes federados:

\begin{abstract}
Art. 10. Constituem objetivos da Reurb, a serem observados pela União, Estados, Distrito Federal e Municípios: I - identificar os núcleos urbanos informais que devam ser regularizados, organizá-los e assegurar a prestação de serviços públicos aos seus ocupantes, de modo a melhorar as condições urbanísticas e ambientais em relação à situação de ocupação informal anterior; II - criar unidades imobiliárias compatíveis com o ordenamento territorial urbano e constituir sobre elas direitos reais em favor dos seus ocupantes; III - ampliar o acesso à terra urbanizada pela população de baixa renda, de modo a priorizar a permanência dos ocupantes nos próprios núcleos urbanos informais regularizados; IV promover a integração social e a geração de emprego e renda; $V$ - estimular a resolução extrajudicial de conflitos, em reforço à consensualidade e à cooperação entre Estado e sociedade; VI - garantir o direito social à moradia digna e às condições de vida adequadas; VII - garantir a efetivação da função social da propriedade; VIII - ordenar o pleno desenvolvimento das funções sociais da cidade e garantir o bem-estar de seus habitantes; IX concretizar o princípio constitucional da eficiência na ocupação e no uso do solo; $X$ - prevenir e desestimular a formação de novos núcleos urbanos informais; XI - conceder direitos reais, preferencialmente em nome da mulher; XII - franquear participação dos interessados nas etapas do processo de regularização fundiária.
\end{abstract}

A novel legislação caracterizou a Reurb em duas modalidades, conforme estabelecido em seu art. 13. A primeira delas é a Reurb de Interesse Social, Reurb$\mathrm{S}$, a ser aplicada aos núcleos urbanos informais ocupados, predominantemente, por população de baixa renda. Merece destaque o fato de a norma não especificar quem seriam as populações de baixa renda, deixando ao alvedrio do Município tal declaração. A segunda modalidade de Reurb identificada na lei é a Regularização Fundiária Urbana de Interesse Específico, Reurb-E, que dirá respeito aos núcleos urbanos informais ocupados por população não qualificada como de baixa renda, e, por estsa razão, não contemplam alguns benefícios propostos para a Reurb-S.

Importante mencionar que a Reurb-E recairá sobre bens públicos que deverão ser adquiridos pelo particular mediante pagamento de valor estabelecido 
pelo Poder Executivo, titular do domínio, e que a referida classificação visa identificar os responsáveis pela implantação ou adequação das obras de infraestrutura essencial e reconhecer o direito à gratuidade das custas e emolumentos notariais e registrais em favor dos adquirentes do domínio das unidades imobiliárias regularizadas, nos termos do disposto no $\S 5^{\circ}$. do art. 13 da Lei №. 13.465/2017.

O art. 14 da Lei ํo. 13.465/2017 prevê aqueles que são legitimados para requerer a Reurb e praticar todos os atos necessários à regularização (incluindo-se o registro). Além dos beneficiários, que poderão agir individual ou coletivamente, diretamente ou por meio de cooperativas habitacionais, associações de moradores, fundações, organizações sociais, organizações da sociedade civil de interesse público ou outras associações civis com atividades voltadas para o desenvolvimento urbano ou regularização fundiária urbana, compõem o rol a União, os Estados, o Distrito Federal e os Municípios, diretamente ou por meio de entidades da administração pública indireta, os proprietários de terrenos, loteadores ou incorporadores; a Defensoria Pública, em nome dos beneficiários hipossuficientes e o Ministério Público.

É importante destacar, ainda que resumidamente, o procedimento a ser realizado quando da instauração da Reurb. O primeiro passo será o requerimento de um dos legitimados que, levado ao Município, dará início à instauração do procedimento por decisão administrativa do ente.

O Município deverá elaborar o projeto urbanístico de regularização fundiária e providenciar à aprovação ambiental, desde que possua órgão ambiental capacitado para tanto. O art. 12 da Lei o․ 13.465/2017 fixa que será considerado "órgão ambiental capacitado o órgão municipal que possua em seus quadros ou à sua disposição profissionais com atribuição técnica para análise e aprovação dos estudos" relacionados aos núcleos urbanos informais situados, total ou parcialmente, em área de preservação permanente ou em área de unidade de conservação de uso sustentável ou de proteção de mananciais. O estudo técnico deverá comprovar que a regularização fundiária acarretará melhorias ambientais em relação à situação de ocupação informal anterior. 
Após a instauração do procedimento administrativo, haverá abertura de prazo para manifestação dos confrontantes e dos titulares dos direitos reais sobre o imóvel. Após o processamento, a autoridade competente decidirá sobre a Reurb e expedirá a Certidão de Regularização Fundiária. Mencionada Certidão será o documento a ser constituído pelo projeto de regularização fundiária aprovado pelo termo de compromisso relativo à sua execução e, no caso da legitimação fundiária e da legitimação de posse, pela listagem dos ocupantes do núcleo urbano informal regularizado, com a qualificação destes e pelos direitos reais que thes foram conferidos.

Por fim, haverá o registro da Certidão de Regularização Fundiária e do Projeto de Regularização Fundiária aprovado no Cartório de Registro de Imóveis da situação da unidade imobiliária regularizada.

Percebe-se que a autonomia municipal foi reverenciada, recaindo sobre a competência do município disciplinar as matérias de interesse local, legislar sobre o uso e a ocupação do solo, ordenar o desenvolvimento da cidade, identificar as áreas passíveis de regularização e o perfil socioeconômico de seus beneficiários, elaborar o projeto a ser adotado e decidir sobre o pedido.

Para que se alcance o fim pretendido pela Lei de Regularização Fundiária, o art. 15 da Lei ํo. 13.465/2017 elencou uma séria de institutos jurídicos passíveis de utilização, dentre eles, merece destaque a disposição do inciso I: a legitimação fundiária e a legitimação de posse.

O instituto da legitimação fundiária, objeto do presente estudo e, por essa razão, único mecanismo a ser abordado, está descrito no art. 23 da Lei №. 13.465/2017:

A legitimação fundiária constitui forma originária de aquisição do direito real de propriedade conferido por ato do poder público, exclusivamente no âmbito da Reurb, àquele que detiver em área pública ou possuir em área privada, como sua, unidade imobiliária com destinação urbana, integrante de núcleo urbano informal consolidado existente em 22 de dezembro de 2016. 
Surge como um mecanismo de reconhecimento de aquisição originária de propriedade.

O dispositivo determina que o ocupante somente fará jus ao benefício se não for concessionário, foreiro ou proprietário de imóvel urbano ou rural; se não houver sido contemplado com legitimação de posse ou fundiária de imóvel urbano com a mesma finalidade, independentemente do núcleo urbano em que se localize; e, se for reconhecido o interesse público da ocupação nos casos de imóvel urbano que não tenha finalidade residencial.

Com efeito, a lei estabelece no art. 23 um marco temporal a ser considerado, sendo possível a legitimação fundiária somente em relação àquelas unidades imobiliárias integrante de núcleo urbano informal consolidado existente em 22 de dezembro de 2016. Todavia, o regramento não prevê um tempo de posse ou detenção necessários para efetivar o direito.

Em decorrência lógica da natureza do instituto, para prosseguir, cumpre ainda analisar a caracterização de um núcleo urbano informal como consolidado. O núcleo urbano será considerado consolidado quando for considerado de difícil remoção, avaliando-se tempo da ocupação, natureza das edificações, localização das vias de circulação e a presença de equipamentos públicos, além de outras circunstâncias analisadas a critério do poder público municipal.

Não se pode ignorar que a avaliação das outras circunstâncias mencionadas no dispositivo passa por ato discricionário do município, o que gera incertezas acerca dos critérios que serão adotados.

Merece destaque o fato de, independentemente do tipo de Reurb verificada, o ocupante adquirir a unidade imobiliária livre de ônus, direitos reais, gravames ou inscrições, existentes em sua matrícula de origem, salvo quando disserem respeito ao próprio legitimado. Além disso, no caso de Reurb-S, o direito poderá ser concedido ainda que os titulares do domínio dos imóveis sejam a União, os Estados, o Distrito Federal e os Municípios, ou as suas entidades vinculadas, nos termos do $\S 4^{\circ}$. do art. 23 da Lei ํ․ 13.465/2017.

Importante salientar que a legitimação fundiária possibilita que o Poder Público encaminhe a Certidão de Regularização Fundiária para registro imediato da 
aquisição da propriedade. Neste caso, não será requerida a apresentação de título individualizado e de cópias da documentação referente à qualificação dos beneficiários, do projeto de regularização fundiária aprovado, da listagem dos ocupantes e sua qualificação e da identificação das áreas que ocupam.

Infere-se que, não obstante haja a regulamentação de projetos e estudos a serem realizados pelo município antes da efetivação da Reurb, tais análises só serão produzidas nos casos que envolvam áreas de preservação permanente, conservação de uso sustentável ou de proteção de mananciais. As exceções previstas e a flexibilização a que se dispõe a norma, facilitam que haja o registro do título no nome dos ocupantes sem que sejam preenchidas determinações constitucionais e legais relacionadas à regularização.

\section{OS IMPACTOS AMBIENTAIS NEGATIVOS DA LEGITIMAÇÃO FUNDIÁRIA}

De acordo com Silva (2011, p.20),

[...] o meio ambiente é [...] a interação do conjunto de elementos naturais, artificiais e culturais que propiciem o desenvolvimento equilibrado da vida em todas as suas formas. A integração busca assumir uma concepção unitária do ambiente, compreensiva dos recursos naturais e culturais.

Por este conceito, bem como pela determinação constitucional prevista no art. 225, que dispõe que "todos têm direito ao meio ambiente ecologicamente equilibrado, bem de uso comum do povo e essencial à sadia qualidade de vida(...)", percebe-se que o meio ambiente é uno. Todavia, existe uma classificação doutrinária-hermenêutica de meio ambiente, e neste sentido, é possível diferenciar o meio ambiente artificial e o meio ambiente natural.

De acordo com esta classificação, o meio ambiente natural ou físico é composto pelos recursos naturais, quais sejam o solo, a água, o ar atmosférico, a flora e a fauna; já o meio ambiente artificial é aquele que abrange praças, 
edificações, ruas, equipamentos públicos, modificações realizadas pelo homem que constituem o espaço urbano.

É perfeitamente possível verificar a ingerência do meio ambiente citadino sobre o meio ambiente natural. $\mathrm{O}$ crescimento desordenado das cidades e da população cosmopolita tem gerado problemas ambientais cada vez mais graves em relação à poluição de igarapés, de região de várzea, ao agravamento de enchentes, dentre outros.

A regularização fundiária, então, é instituto utilizado para regularizar o direito real daquele que habita a terra e promover a urbanização do local. O esforço do Poder Público migrou da construção de moradias em massa, como preconizado pelo Programa Minha Casa Minha Vida, para a legitimação e titulação de edificações realizadas pela autoconstrução, ou seja, pelos próprios ocupantes das cidades, sem qualquer controle ou planejamento. A equidade, a inclusão, a justiça socioambiental e o bem-estar são esquecidos, enquanto aqueles que não possuem o registro das propriedades em que vivem acreditam que o título será suficiente para a obtenção de direitos que nunca conheceram.

A Lei no. 10.257/2001, em seu art. $2^{\circ}$., inciso XIV, destaca que na urbanização das áreas ocupadas pela população de baixa renda, as normas deverão considerar não só a situação socioeconômica da população ocupante, mas também as normas ambientais. Entretanto, em uma análise comparativa superficial entre o Programa Minha Casa Minha Vida e a Lei da Reurb, identifica-se, preliminarmente, que a nova lei tende a priorizar a titulação das propriedades sem maiores cuidados quanto à regulação do uso do solo, flexibilizando o registro dos imóveis sem observar a sustentabilidade ambiental.

A legalização de construções informais intensificou um fenômeno, há muito observado no País: o de segregação das populações carentes, uma vez que beneficia pessoas que se utilizam de mecanismos, como o da regularização fundiária, para dar início a ocupações irregulares do solo e incentiva que essa prática seja reiterada.

Não obstante a legalização da moradia (vista aqui como titulação dos ocupantes) garanta, de fato, direitos sociopolíticos às populações nas cidades, ela 
não é suficiente para a solução da desordem urbana em todas as suas facetas. Observa-se que a política de urbanização, não atinge as necessidades da massa. A insegurança fundiária limita os investimentos do Poder Público e a proteção jurídica do acesso ao solo.

A precariedade do controle, do uso e da ocupação dos espaços urbanos gera uma série de desordens no meio ambiente das cidades: violência, expulsões arbitrárias, ausência de serviços públicos adequados, poluição, falta de sensação de pertencimento dos ocupantes, ineficácia do ordenamento territorial, dentre outros.

A Lei no. 13.465/2017 dispõe que o projeto urbanístico de regularização fundiária deverá conter:

Art. 36. O projeto urbanístico de regularização fundiária deverá conter, no mínimo, indicação: I - das áreas ocupadas, do sistema viário e das unidades imobiliárias, existentes ou projetadas; II - das unidades imobiliárias a serem regularizadas, suas características, área, confrontações, localização, nome do logradouro e número de sua designação cadastral, se houver; III quando for o caso, das quadras e suas subdivisões em lotes ou as frações ideais vinculadas à unidade regularizada; IV - dos logradouros, espaços livres, áreas destinadas a edifícios públicos e outros equipamentos urbanos, quando houver; V - de eventuais áreas já usucapidas; VI - das medidas de adequação para correção das desconformidades, quando necessárias; VII das medidas de adequação da mobilidade, acessibilidade, infraestrutura e relocação de edificações, quando necessárias; VIII - das obras de infraestrutura essencial, quando necessárias; IX - de outros requisitos que sejam definidos pelo Município.

Assim, o projeto urbanístico de regularização fundiária deverá contar, necessariamente, com medidas de adequação para correção das desconformidades, de adequação da mobilidade, acessibilidade, infraestrutura e realocação de edificações e com as obras de infraestrutura essencial. Parece impossível não se questionar sobre como seriam realizadas as adequações necessárias para a correção das desconformidades mencionadas no diploma legal, ou sobre como seriam realizadas as obras de acessibilidade e infraestrutura, lembrando-se aqui, que os núcleos urbanos a serem legitimados são os consolidados, ou seja, de difícil remoção. 
Os parágrafos seguintes do artigo 36 da Lei №. 13.465/2017 elencam os equipamentos a serem considerados com infraestrutura essencial e descrevem regras a serem obedecidas pelo poder público:

\begin{abstract}
Art. 36 [...] omissis. $\S 1^{\circ}$ Para fins desta Lei, considera-se infraestrutura essencial os seguintes equipamentos: I - sistema de abastecimento de água potável, coletivo ou individual; II - sistema de coleta e tratamento do esgotamento sanitário, coletivo ou individual; III - rede de energia elétrica domiciliar; IV - soluções de drenagem, quando necessário; e V - outros equipamentos a serem definidos pelos Municípios em função das necessidades locais e características regionais. $\S 2^{\circ}$ A Reurb pode ser implementada por etapas, abrangendo o núcleo urbano informal de forma total ou parcial. § $3^{\circ}$ As obras de implantação de infraestrutura essencial, de equipamentos comunitários e de melhoria habitacional, bem como sua manutenção, podem ser realizadas antes, durante ou após a conclusão da Reurb. $\S 4^{\circ}$ O Município definirá os requisitos para elaboração do projeto de regularização, no que se refere aos desenhos, ao memorial descritivo e ao cronograma físico de obras e serviços a serem realizados, se for o caso. $\S$ 50 A planta e o memorial descritivo deverão ser assinados por profissional legalmente habilitado, dispensada a apresentação de Anotação de Responsabilidade Técnica (ART) no Conselho Regional de Engenharia e Agronomia (Crea) ou de Registro de Responsabilidade Técnica (RRT) no Conselho de Arquitetura e Urbanismo (CAU), quando o responsável técnico for servidor ou empregado público.
\end{abstract}

Por fim, a Lei ㄲo. 13.465/2017 descreve regras específicas a serem seguidas pelo poder público em relação à disponibilização da infraestrutura básica:

Art. 37. Na Reurb-S, caberá ao poder público competente, diretamente ou por meio da administração pública indireta, implementar a infraestrutura essencial, os equipamentos comunitários e as melhorias habitacionais previstos nos projetos de regularização, assim como arcar com os ônus de sua manutenção. Art. 38. Na Reurb-E, o Distrito Federal ou os Municípios deverão definir, por ocasião da aprovação dos projetos de regularização fundiária, nos limites da legislação de regência, os responsáveis pela: I implantação dos sistemas viários; II - implantação da infraestrutura essencial e dos equipamentos públicos ou comunitários, quando for o caso; e III - implementação das medidas de mitigação e compensação urbanística e ambiental, e dos estudos técnicos, quando for 0 caso. $\S 1^{\circ}$ As responsabilidades de que trata o caput deste artigo poderão ser atribuídas aos beneficiários da Reurb-E. $\S 2^{\circ}$ Os responsáveis pela adoção de medidas de mitigação e compensação urbanística e ambiental deverão celebrar termo de compromisso com as autoridades competentes como condição de aprovação da Reurb-E. 
Na prática, o que se percebe é que legitimação fundiária servirá apenas para titular os ocupantes, sem nenhuma política de adequação ao plano diretor, sem planejamento pelo município, que apenas estará regulamentando o que não conseguiu impedir, sem ordenamento territorial, políticas públicas de segurança e educação ambiental.

A legitimação fundiária dos núcleos informais consolidados surge como mecanismo de solução para o abismo existente entre o preceito constitucional de moradia digna e a prática observada no Brasil.

A regra é que as limitações existentes ao direito das populações carentes não se referem apenas à falta de titulação dos ocupantes do solo. O problema vai além. Falta de planejamento, de infraestrutura, de segurança, de educação ambiental, ofensa às funções urbanísticas de habitação, lazer, trabalho são observadas todos os dias nas periferias das cidades brasileiras.

Um instituto que visa flexibilizar a regularização de direitos reais não só das populações menos favorecidas, como de todos aqueles que se encontrem em situação de irregularidade e preencham alguns requisitos legais. Ocorre que o registro dessas áreas não impedirá que outras surjam posteriormente, ou que legislações vindouras prorroguem a data limite para a realização da legitimação, ou, ainda, que pessoas de má-fé, forjem documentos para serem incluídos no rol de beneficiários do sistema.

Por uma perspectiva juspositivista, se a Carta Magna dispõe sobre a necessidade de estudo prévio de impacto ambiental antes da realização de algumas atividades com potencial para degradar o meio ambiente como um todo, por qual motivo a Reurb exclui o estudo e projeto urbanístico nos casos em que os núcleos informais não estejam localizados em áreas de proteção ambiental?

Percebe-se uma relação cristalina entre o estudo de impacto ambiental e o meio ambiente das cidades. Se assim não o fosse, como seriam verificados os impactos que a edificação de um prédio na faixa litorânea poderia causar à circulação do ar, por exemplo? Ou ainda, os assentamentos urbanos, por meio do parcelamento do solo e da regularização fundiária urbana? 
Esta relação torna-se ainda mais significativa dada à tendência, aparentemente inexorável, de expansão e de universalização do meio ambiente citadino, seja diretamente, seja por efeitos e consequências indiretas, o que demanda soluções jurídicas, tais como o estudo técnico e os projetos de regularização fundiária, a fim de harmonizar o processo de urbanização com a conservação e, nos casos possíveis, a preservação do meio ambiente.

O instituto da legitimação fundiária não abarca a função socioambiental da propriedade. Ao permitir a Reurb nos núcleos informais consolidados considerando como fato preponderante a difícil remoção, a Lei acaba respaldando a fragilidade do Estado em fazer cumprir os ditames constitucionais e legais e aqueles que violaram as normas urbanísticas.

A emissão de títulos aos ocupantes das áreas destacadas pelos municípios não equaciona deveres sociais, econômicos e ambientais. A intenção legal ultrapassa a titulação, ela espera que se impute ao Estado a obrigação de gerar moradia digna àqueles menos favorecidos e que necessitam da proteção pública. Água encanada, saneamento básico, energia elétrica, vias circuláveis, praças, arborização, limpeza, dentre outros equipamentos públicos, são necessários para que se alcance tal fim.

A ordenação dos espaços habitáveis é de observância primordial para a obediência ao que se entende por dignidade da pessoa humana. Só assim, seria possível, se não evitar, diminuir, os efeitos negativos da falta de ordenamento territorial sobre o meio ambiente urbano.

\section{CONSIDERAÇÕES FINAIS}

A problemática que motivou esta pesquisa foi a de verificar quais seriam os reflexos, no meio ambiente urbano, da legitimação fundiária dos núcleos urbanos informais consolidados.

Os objetivos da pesquisa foram alcançados na medida em que foi analisado o instituto da legitimação fundiária, mecanismo de aquisição originária de 
propriedade, em cotejo com diretrizes constitucionais por vezes conflitantes - o direito fundamental à moradia digna e o princípio do desenvolvimento sustentável, bem como o princípio do ordenamento territorial e o direito ao meio ambiente urbano sadio e equilibrado.

Concluiu-se que a legitimação fundiária é instrumento frágil, que não solucionará o problema da moradia digna no Brasil e trará consequências graves ao meio ambiente das cidades. A exclusão do estudo ambiental e dos projetos de urbanização em todos os casos que não envolvam áreas de proteção ambiental ocasionará um crescimento desordenado é de impossível correção. Além disso, a titulação de terras sem necessidade de qualificação ou comprovação de destinação tende a facilitar a ação de pessoas que agem de má-fé e não teriam direito ao benefício.

Por fim, conclui-se que, para que haja uma real observância dos preceitos constitucionais, é necessário que o Estado cumpra o seu dever de organização das cidades e pare de procurar mecanismos para aplacar as obrigações não cumpridas.

\section{REFERÊNCIAS}

AMENDOLA, Mônica. Uma avaliação do ordenamento territorial no processo de planejamento governamental: estudo do Rio de Janeiro. Orientadora: Ana Maria Marques Camarga Marangoni. São Paulo, 2011 Faculdade de Filosofia, Letras e Ciências Humanas da Universidade de São Paulo.

BRASIL. Constituição da República Federativa do Brasil. Congresso Nacional, Brasília, 1988.

. Lei Federal no 6.766/1979. Congresso Nacional, Brasília, 1979.

. Lei Federal no 10.257/2001. Congresso Nacional, Brasília, 2001.

. Lei Federal no 11.977/2009. Congresso Nacional, Brasília, 2009.

. Lei Federal no 13.465/2017. Congresso Nacional, Brasília, 2017. 
CARMO, Fernanda do. Princípios constitucionais do ordenamento do território. Sociologia, Problemas e Práticas [Online], NE, 2016. Disponível em: http://journals.openedition.org/spp/2620. Acesso em: 11 jun 2019

Cartilha - regularização fundiária urbana - aspectos práticos da lei 13.465/2017. Disponível em: https://www.sinoreges.org.br/_Documentos/Upload_Conteudo/arquivos/CARTILHA_REGULARIZACAO _FUNDIARIA_URBANA_2017.pdf. Acesso em: 29 mai. 2019.

EMILIASI, Demetrios. Regularização Fundiária e Direito de Laje. São Paulo: BH Editora, 2019.

FARIAS, Paulo José Leite. Respeito às funções urbanísticas e a prevenção da criminalidade urbana: uma visão integrada à luz da Escola de Chicago. Boletim Científico, Escola Superior do Ministério Público da União. Brasília, a-4 - n. 16, p. 19-109,jul/set 2005

FERREIRA FILHO, Paulo Sérgio. Ministério Público e a Regularização Fundiária Urbana em Áreas de Preservação Permanente: análises econômica e comportamental. 1. ed. Rio de Janeiro: Lumen Juris, 2017.

FERREIRA, Maria Manuela Malheiro Dias. Desenvolvimento Urbano Sustentável: O papel dos Cidadãos. In: COLÓQUIO IBÉRICO DE GEOGRAFIA, 10., 2005, Évora. Actas. Évora: Universidade de Évora, 2005. p. 1 - 111. Disponível em:

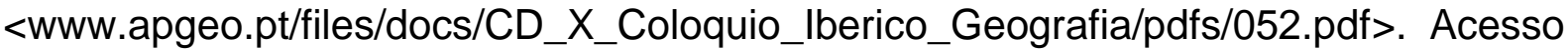
em: 14 jun. 2019.

HAVRENNE, Michel François Drizul. Regularização Fundiária Rural. Curitiba: Juruá, 2018.

LOUREIRO, Luiz Guilherme. Registros Públicos: teoria e prática. 9a. ed. rev., atual. e ampl. Salvador: Editora Juspodium, 2018.

MELO, Marco Aurélio Bezerra de. Brevíssimo ensaio sobre a função socioambiental da propriedade. In: GenJurídico, São Paulo, set 2018. Disponível em: http://genjuridico.com.br/2018/09/14/brevissimo-ensaio-sobre-funcaosocioambiental-da-propriedade/. Acesso em 15 jun 2018.

MOTA, Maurício Jorge Pereira. TORRES, Marcos Alcino de Azevedo. MOURA, Emerson Affonso da Costa. Direito à moradia e Regularização Fundiária. Rio de Janeiro: LumenJuris, 2018.

NAÇÕES UNIDAS NO BRASIL. A Agenda 2030 para o Desenvolvimento Sustentável. Disponível em: https://nacoesunidas.org/pos2015/agenda2030. Acesso em: 29 mai 2019. 
NEVES, Edson Alvisi; SANTOS, Fábio Roberto de Oliveira; SEPÚLVEDA, Fernanda. Direito à Moradia: $O$ papel da Jurisdição na redistribuição do solo urbano. Rio de Janeiro: Lumen Juris, 2017.

NOSSO FUTURO COMUM (Relatório Brundtland). Comissão Mundial sobre Meio Ambiente e Desenvolvimento. Rio de Janeiro: Editora da Fundação Getúlio Vargas, 1988.

SILVA, lohana Cristina Nogueira; ALMEIDA, Paulo Santos de. Regularização fundiária em áreas de conservação: análise da legislação ambiental e seus reflexos nas populações locais vulneráveis e no meio ambiente entre 2000-2010 no reservatório billings. Revista Direito Ambiental e Sociedade, Caxias do Sul, v. 7, n. 2, p.239-264, maio 2017. Quadrimestral. Disponível em: $<$ http://www.ucs.br/etc/revistas/index.php/direitoambiental/article/view/4055>. Acesso em: 1 jun. 2019.

SILVA, José Afonso da. Direito Ambiental Constitucional. 9. ed. atual. São Paulo: Malheiros, 2011.

. Direito Urbanístico Brasileiro. 8. ed. atual. São Paulo: Malheiros, 2018. 